\title{
A SYSTEMIC BELIEF APPROACH TO EPILEPTIC SEIZURES: A CASE OF BEING SPELLBOUND
}

Lorraine M. Wright

Peggy Simpson

ABSTRACT: A systemic treatment approach, namely systemic belief therapy, has been found to be useful when dealing with families constraining beliefs when experiencing physical health problems. Two interventions which facilitate the altering of constraining beliefs are the externalization of physical symptoms and therapeutic letters. Epileptic seizures are examined in the context of the interaction between families and health care professionals. A case example is presented which highlights the use of this systemic approach to assist a young couple in challenging their beliefs about their ability to control and monitor epileptic seizures.

\section{INTRODUCTION}

Epilepsy is a major neurological disorder of unknown etiology, second only to stroke in frequency (Adams \& Victor, 1981). Epilepsy has been misunderstood and feared primarily because of the often frightening manifestation of seizure activity. The incidence of epilepsy is that of 30-50 new cases/100,000 per year (Schoenberg, 1985). The morbidity and mortality rates are difficult to establish as seizure activity can result in various accidental deaths. As well, individuals with epilepsy have a higher rate of suicide and attempted suicide (Schoenberg, 1985).

There is a great social stigma attached to epilepsy and individuals may suffer more from the psychosocial implications than the

Lorraine M. Wright, RN, PhD, is director, Family Nursing Unit, and professor, Faculty of Nursing, University of Calgary, 2500 University Drive, NW, Calgary, Alberta T2N 1N4, CANADA.

Peggy Simpson, RN, MN, is family clinical nurse specialist, Nursing Service, Department of Orthopedics, Foothills Hospital, Calgary, Alberta T2N 2T9 CANADA.

Reprint requests should be addressed to the first author. 
physiological implications (Dodrill, Beier, Kasparick, Tacke, Tacke, \& Siang -Yang Tan, 1984). Although some individuals may have their seizure activity eliminated by medication, the possibility of having a seizure is ever present and may be hazardous in certain environments. The unpredictability of seizure onset makes epilepsy particularly problematic for individuals and their families.

Society's attitudes of ignorance and fear toward epilepsy may infuence the individual's beliefs about self and may account for the poor self-esteem evident in many individuals experiencing epilepsy (Mittan, Locke, \& Gatica, 1983). In addition, the beliefs about the etiology and the treatment of the epilepsy influence how the individ ual and the family manage the problem and the expectations they have for treatment (Harkaway \& Madsen, 1989; Masland, 1985). Most of the research examining epilepsy within the context of the family has focused on children with seizures. Ziegler (1982) discussed an interactional model of family functioning to explain family responses to a seizure disorder in a child. Family functioning was most influenced by the degree to which the patient and the family experienced disruption in their feelings of competence and control in relation to the seizure activity. Seizures tended to create an actual rupture in the control of the individual. This rupture in control affected numerous interactional patterns which disrupted the automony of the marital dyad and the family system as a whole.

Although there is some evidence of the impact of neurologically impaired individuals on the family (Kerns \& Curley, 1985), the adult experience of the reciprocal impact of epilepsy on the lamily and the influence of the family on epilepsy has not been well documented.

The application of a systems approach in clinical practice can yield important information about families' experiences of seizure dis: orders. An increased understanding of family dynamics related to seizure disorder could also lead to the development of imnovative sys. temic interventions to facilitate change. This article presents the senior author's systemic approach, namely Systemic Belief Therapy (Wright, Watson, \& Bell, 1990) as a potentially useful one with farnihes experiencing seizure disorders. In addition to the use of interventive questions which explore and draw forth both constraining and facilitative beliefs, our clinical team also utilized the psychotherapy technique of externalization of the problem (i.e., epileptic seizures) (Tomm, 1989; White, 1984; White \& Epston, 1989) and therapeutic letters (Epston, 1986; White \& Epston, 1989; Wood \& Uhl, 1988: Wright, Watson, \& Bell, 1990) to introduce more facilitative beliefs. 
A clinical case example is presented to illustrate the application of this particular systemic approach.

\section{SYSTEMIC TREATMENT OF EPILEPTIC SEIZURES}

\section{Systemic Belief Therapy}

Systemic Belief Therapy focuses on the interaction between the symptom or presenting problem and the beliefs about the problem (Wright, Watson, \& Bell, 1990). Finding out what clients believe about the problem/symptom is no easy task. Thompson (1986) wrote an entire text examining different levels of culture and the various ways in which they can have ideological effects. However, at the conclusion of the book, he asked the question, "How much can we know about what ordinary people really believe?" (p. 123). We are more optimistic than Thompson and believe that through the medium of therapeutic conversations with clients, opportunities are afforded to draw forth beliefs through the asking of questions by both client and interviewer (Wright, 1990). During the assessment phase, we attempt to elicit an understanding of each family members' belief's surrounding the problem. Distinctions are then made by the interviewer between constraining and facilitative beliefs.

Constraining beliefs evolve from interactional, social, and cultural contexts. However, we are encouraged by Needham's warning to ethnographers that "people do not necessarily believe what their culture trains them to say" (Needham, 1972). Constraining beliefs inhibit the automony of the individual and the farmily system by restricting options for alternate solutions to problems. Constraining beliefs may be perturbed by introducing new connections between beliefs and behaviors. Change occurs when there is a shift in the constraining beliefs.

Facilitative beliefs, which also evolve from interactional, social and cultural contents increase options for alternate solutions to problems. Family interviewers can perturb the family system by introducing new ideas or opinions which may draw forth facilitative beliefs from family members, thereby increasing the automony of the family system. The aim of the interviewer is to create a context for change and to offer an alternate belief about the problem so that the family can open space to discover their own solutions.

What we believe is the most powerful option of all. Beliefs shape the way families adapt to chronic and life-threatening illness. A fam- 
ily's belief about the etiology, treatment, and prognosis of an ilmess needs to be assessed as well as their beliefs about control of the symptoms. The family's sense of mastery and control over symptoms (Rolland, 1987) is particularly relevant in families experiencing epilepsy. The unexpected and intrusive nature of seizures poses a threat to the sense of control and automony within a family system.

\section{CASE STUDY}

Profile of Family

The N. family consisted of Tom, a 27-yearold husband and father, who was employed as a furnace technician, and was married to Sandy, a 24-year-old homemaker and their two children, Andrew, seven years-old and Denise, six years old. The children were from a previous common-law relationship of Sandy's. Tom had legally adopted the children. Tom's parents divorced when he was six years old, and he was raised by an aunt and uncle. Tom had a history of alcohol abuse but was currently attending Alcoholics Anonymous meetings and at the time of the family meetings he reported being a non-drinker.

\section{Presenting Problem}

Sandy had recently been assessed on a neurosurgical telemetry hospital unit for uncontrollable seizures. Sandy had experienced "spells" since age 14 and was diagnosed with left temporal lobe epilepsy at age 22. Sandy experienced complex partial seizures lasting from 30-60 seconds as well as other types of "spells". These other spells were described as periods of weakness with memory loss and an inability to speak. All "spells" left Sandy feeling helpless and upset. Pharmacological intervention included Dilantin $200 \mathrm{mg}$, twice daily and Tegretol $500 \mathrm{mgm}$. morning and evening. The family was referred to our clinical team for assistance in coping with escalating marital conflict and increased frequency of epileptic seizures.

\section{Systemic Treatment}

Our clinical team utilized the Systemic Belief Therapy (SBT) (Wright, Watson, \& Bell, 1990) approach to assess families. Supplementing our assessment of beliefs is the Calgary Family Assessment Model, which is a multidimensional framework used to assess the 
structural, developmental and functional components of the family system (Wright \& Leahey, 1984). Primary emphasis during the past few years, however, has been on the assessment of individual family members' beliefs related to the presenting problem (i.e., etiology, treatment, prognosis, role of the family, and role of the health care professional) (Wright \& Leahey, 1987; Wright \& Watson, 1988; Wright, Watson, \& Bell, 1990).

Session One. The initial assessment focused on the beliefs and family dynamics surrounding the marital conflict as this was the most distressing problem identified by the family in the first session. Constraining beliefs of Sandy about herself included: "I don't like myself. I don't think I'm a good person. I don't see how anyone can like me. If Tom goes out of my life, it will reinforce the fact that I'm not a nice person."

In session one, questions were designed to target Sandy's constraining beliefs related to self and the couple's constraining beliefs about their marital relationship. The questions we used to challenge constraining beliefs were often reflexive in nature (Tomm, 1988), that is, questions that would invite family members to take a meta-position to their behavior and/or beliefs. Hypothetical or future-oriented questions, which are examples of reflexive questions, may challenge an existing family belief or advance a new one. These types of questions offer new information which opens space for the family to "see" new possibilities of how they can evolve in their own unique way (Boscolo, Cechin, Hoffman, \& Penn, 1987; Tomm, 1988).

Questions challenging the couple's belief system included:

What is your life like for you now? What would life be like for you if the fighting stopped? Does Sandy ever worry she will lose her ability to attract Tom's attention? What is the best advice Sandy can give herself when she's ready to give up being so self-denegrating?

At the end of the session we offered an alternate belief which was designed to challenge the negative beliefs/opinions Sandy had about herself and her belief about the inevitable failure of the marriage. Sandy and Tom were commended individually and as a couple. The couple were described as unique (the way they met), as having a secret key for marriage (i.e., still together after two years against all odds) and having a potion for passion. With this intervention, the team provided an alternate belief of the couple as individuals and of the marriage to try and create a context for change.

text for change. 
Following the team's positive comments in the first session, Sandy felt prompted to visit an old and trusted family physician and clarify his ideas about her epilepsy and her abilities. From this visit Sandy informed us that she learned that she knew a lot more about herself than most people gave her credit for and that she did indeed have the capability to handle her problems. Sandy's family physician told her that in his opinion her intellectual level was high enough that she could do anything she wanted to do. The next day, Sandy went out and obtained a job.

Session two. The belefs and family dynamics surrounding the epileptic seizures were the focus of the second session. At the beginning of the session, the couple reported major changes over a two week period. Sandy had obtained a part-time job as playground supervisor at the local school. The disagreements between Sandy and Tom decreased from every day to every third day. Sandy was also less quick to get angry at Andrew and Denise. But the most astounding change of all was that Sandy had been seizure-free since the last ses. sion. Previously Sandy had experienced 3-4 seizures every day for the past six months.

Sandy also reported to our clinical team about her recent visit to her family physician. At this meeting she was given the opportunity to read and discuss the medical consultant's report. In the consultant's report, he stated his diagnosis of Sandy: an immature 24 year old with a personality disorder. As she was relating the medical con sultant's diagnosis, she suddenly stopped talking, her eyes rolled back in her head, she moaned softly and it was obvious that Sandy was experiencing a seizure. The interviewer asked the husband what would be the best thing to do at this point and how long would the seizure last? Tom responded to the interviewer's questions by explaining: "She is having one of her spells. The best thing to do is just sit and wait for it to pass. If she is standing, I put my arms around her and make sure she doesn't fall down. She can't understand if I talk to her. If I just hold her that is the best thing."

Following the dramatic occurrence of a seizure, the focus switched to an exploration of the couple's beliefs about epileptic seizures. Questions were asked that would draw forth the couple's beliefs about the influence they have over the spells and the influence of the spells on them (White, 1988; White \& Epston, 1989). Sandy expressed the be lief that with increased stress the spells become stronger and more rude. With decreased stress, Sandy stated she has some control over the spells.

After we experienced one of the epileptic seizures first hand, we began to co-evolve a new description of the problem by externalizing the seizure. Externalization of the problem (i.e., the seizures in this 
instance) is a very innovative psychotherapy intervention developed by Michael White of Australia (Tomm, 1989; White, 1986; White, 1984; White \& Epston, 1989). It evolves separating the problem of the seizure from the personal identity of the client. The following dialogue between the interviewer and Sandy gives a brief example of how questions and comments are phrased when a problem is being externalized.

Interviewer: The spells are so intrusive and rude, they seem to take control of the whole situation.

Tom: Oh, yeah. It happens all the time.

Interviewer: Is there anything you've done that helps gain more control of them?

Tom: I've tried everything, other than smacking her.

Interviewer: It seems that everyone is at their mercy.

Tom: Yes, they happen anywhere, anytime.

By externalizing the problem of epileptic seizures, the seizures were described as rude and intrusive. They (the seizures) had interrupted our therapeutic conversation. Externalizing the problem of seizures took away blame from the client and created possibilities for new beliefs about the problem. In turn, new beliefs created more solution options for the family.

Externalization is further achieved by introducing questions that encourage family members to map the influence of the problem in their lives and their influence in the life of the problem. This is called relative influence questioning (White, 1988). Relative influence questioning (White, 1988) elucidated the influence Tom and Sandy had over the impact of seizures on their lives and contrasted it with the amount of influence the seizures had in controlling Tom and Sandy. This created a double description (White, 1986). The couple could now view the problem from two perspectives rather than one.

The double description challenges family restraints or problematic beliefs and thus triggers new responses for the discovery of new solutions. The two-sided or circular understanding of the problem aides in the creation of the double description. Complementary questions are reflexive in nature and are designed to explore the participation of all parties to the interaction in maintaining the problem and to create a double description.

Examples of complementary questions asked by the interviewer were: you?

Can you tell when the spell is beginning to get a hold of Is the spell a friend or a foe? 
How often could you tolerate the spells taking over in your lives?

Was there a time when the spell tried to take over but was unsuccessful because you were able to keep control?

At the end of the second session we decided to write a therapeutic letter. The first draft of the letter was read at the end of the session. The final letter was mailed approximately one week post-session.

White and Epston (1989) use the narrative mode to present problems as an oppressive dominant story or knowledge through the use of therapeutic letters. The solution is constructed in terms of opening space for the authoring of new stories. New stories embed new beliefs that one may now generate about oneself. The therapist and the client co-create a solution story. White and Epston (1989) also use narrative to elaborate the picture of the client conquering the problem. The language is metaphorical in nature and can create a context for change.

The letter to Tom and Sandy focused on the positive aspects of the couple's response to each other during the session. In addition, we wanted to counter the very negative beliefs and labels that the medical consultant had given to Sandy. We wanted to offer a new description and belief (i.e., the beginnings of a new story) that we had about her and about them as a couple. We also wanted to embed the notion of the separation of the epileptic seizures from Sandy and Tom and give them our vote of confidence in their present and future ability to deal with the spells. Also, we learned that on this particular interview day, it was Sandy's birthday and that a letter could be our present to her.

\section{Letter Following Session \#2.-A Birthday Letter}

Dear Tom and Sandy:

During our first meeting we were impressed by the two of you as a couple. Today, during our second meeting, we were struck by the tremendous caring and consideration you showed for each other. We were able to observe first-hand how you Tom showed much concern for Sandy when she was taken over by the spell. We also saw how you Sandy, reached out and expressed your caring for Tom by touching his hand. After the intrusive spell, you showed your closeness by holding hands.

We were pleased to be able to witness a spell first-hand. It came in rudely and interrupted a very significant part of 
our conversation and the information, you Sandy, were about to share with us. You and Tom commented that these spells are not friendly and seem to side with stressful times and negative emotion. From what we witnessed today, we agree that this seems to be the case. However, we were amazed when you said the spells had stopped intruding so often in your lives: from taking over 3 times a day to only once in the past 2 and $1 / 2$ weeks. We wish to congratulate you both but especially you Sandy, for your tremendous accomplishment in sending the spells on "vacation" rather than have them hanging around as rude, unwanted house guests.

In spite of the way the spells disrupt things, you Tom, are willing to have them take over once a month. You, Sandy, are willing to allow them to intrude 2-3 times a week. We have tremendous respect for your tolerance.

We are very optimistic with what we have learned about you, Sandy, in our last two meetings. You told us several things that you have done for yourself which have sent the spells packing. These included getting a job, getting more exercise, taking less caffeine, and being less stressed. You told us of the time you were even able to maintain control while the spell tried to take over in the kitchen. We believe that as you try out even more of your ideas you will gain more and more strength against the spells.

During this struggle we have every confidence in you Tom, and you Sandy, in your ability as a team. This is because Sandy, in the first session you said you believe Tom really loves you. You, Tom, said you would do anything to make the marriage work. In spite of your differences you two are allies.

As a clinical team we perceive you, Sandy, as an intelligent, responsible young woman who was born with a great inner strength to be victorious in life. For you, one of the greatest challenges has been dealing with epilepsy and the annoying rude spells that have been so intrusive in your life. Unfortunately the spells are not the only rude things in life. There will always be some people who never really know you well and will short-change your capabilities to the point of claiming you are immature. Some will even go so far as to say that you have a personality disorder. We have complete confidence that neither of you will allow these opinions to invite you to have unnecessary spells; conflict between the two of you; discouragement; or depression.

So on this major milestone, Sandy, your 25 th birthday, we wish you continued success in coping with the stresses 
and challenges that you have been presented with in life. We believe that you are more mature than most 25 year olds we have know; and like Tom, we are very attracted by your intelligence.

\section{Happy Birthday!}

Sincerely,

\section{Peggy Simpson, RN, BN Lorraine M. Wright, RN, PhD Graduate Student Director, Family Nursing Unit Professor, Faculty of Nursing and other members of our clinical team.}

Session Three. In the third session the couple continued to report major changes: Sandy had organized a surprise birthday party for Tom. This was the first time she had ever planned a party; Sandy was invited to be on the Parents Advisory Council; Tom's friends complimented her on her inner emotional strength; Sandy was able to stand up to her family's criticisms and consequently they were treating her with more respect. Sandy was also describing herself in a more positive way by saying she was doing a good job with her family, she was a good financial manager, and able to stand up for her values. Sandy had experienced 3 seizures during the week she planned Tom's birthday party.

\section{Letter Following Session \#3:-A Letter of Praise and Warning}

Dear Tom and Sandy:

Because of the late start, our last meeting was a bit rushed. However, since that meeting our team had a chance to discuss your situation and we would like to share our ideas with you now.

The team commented that you Sandy seemed to be having an "off-night". One thing that became very apparent during the meeting was how tired you both seemed. It made us appreciate how exhausting the situation must be for you. Tom, you are currently suffering a neck injury. Sandy, since September you have taken on more responsibility. You are now busy juggling the care and management of your children, your home, your job, Tom being at home, and the spells. You have a lot to cope with and your organizational skills are being pushed to the limit. 
During our meeting with you both, we were able to get a better understanding of how much influence the spells have in your lives. Sandy, they have a real ability to knock your confidence. The spells also entice you into a "down-in-thedumps" lifestyle. They were also rude in their attempt to disrupt your plans for Tom's surprise birthday party. They even have a sneaky way of taking over the topic of conversation when the two of you could be talking about your achievements, planning fun times together as a couple or a family, or sharing new ideas for a new direction in your life - but what happens?? The spells invite you to spend $30-40 \%$ of this valuable "talk-tine" discussing them. They are really unwilling to give up their high status in your lives.

The team is impressed with the success you continue to experience in your new direction in life despite the spell's strong negative influence. Tom, you told us of the confidence and self-respect Sandy now shows by standing up to others in defending her good judgement and values. You mentioned that the more Sandy's family view her as a mature and responsible woman, they are laying off from criticizing and showing more respect.

Remember how nervous you were about applying for a job in September, Sandy? However, you were hired at the school as playground supervisor and your co-workers were so impressed with your confidence and ability that now the Vice-Principal has invited you to be on the Parents' Advisory Council. We are very impressed.

But that isn't all. Next we heard that you decided to tackle the social circuit. We were delighted that you were able to overcome your apprehension and the influence of the spells to express your love for Tom in a new way. To plan a surprise party as your first social function takes a lot of stamina and creativity. All your friends came and it was a wonderful success! What does this tell you about your ability as a hostess? What does this say about your ability to socialize with others? What does this say about people wanting to spend their "fun times" with you and Tom?

Tom, the team couldn't get over you. You are the captain of Sandy's cheering team. We noticed how you continued to praise Sandy for her efforts and you were encouraging her to show even more of her ability. You told us how good she is at her job and that she had the ability to take over as librarian at the school, if she wanted. You are right there coaching her in her efforts to stand up for herself. You seem to understand 
what a drain it is on her to manage the house the kids and the spells. Sandy said that all she needed to do was ask for help and you would be right there. What a team!

Tom, we agreed with you in your frustration at the spells having such an influence on your time with Sandy. You both have decided to reduce the spells status in your lives. This of course will tend to frustrate the spells and they may become even more sneaky in their efforts to undermine your new found successes in life.

The team is very impressed with the continuing control you have in directing your lives. You both seem to be coming up with many good ideas in enhancing your team effort to cut down the influence of the spells in your lives. We look forward to seeing you at our next appointment.

Sincerely,

\begin{tabular}{|c|c|}
\hline Peggy Simpson, RN, BN & Lorraine M. Wright, RN, PhD \\
\hline udent & $\begin{array}{l}\text { Director, Family Nursing Unit } \\
\text { Professor, Faculty of Nursing }\end{array}$ \\
\hline
\end{tabular}

P.S. We do have one last question. Which team would you place the visits to the Dr., your bloodwork and your medications? Do these belong on the "cheering team" to help you win over the influence of the spells or do they belong on the "intrusive team" which sides with the spells?

Session four. The fourth session was a wrapup session. The couple continued to report positive changes. They felt there was no further need to attend sessions as they were tired of the spells being the focus of attention. They said that any current maxital difficulties they could deal with themselves.

\section{Letter Following Session \#-Final Session-Letter of New Beginnings}

Dear Tom and Sandy:

We have had a few thoughts since we last met for the final wrap-up session. The team and $I$ could not get over the changes you have made in your marriage. You both came up with such good ideas on how to iron out the rough patches in the way you communicate with each other. You are also spending more "fun" times together. As a result you are both more relaxed with each other and the children. What a difference that has made for family time together! 
Both of you have begun to discover the many positive things about yourselves and about each other. Isn't it amazing how there is more time for this now that you have put the intrusive spells in their rightful place.

We appreciate the fact that you realized you no longer needed to come to the sessions here at the Family Nursing Unit. You are now yery resourceful in being able to tackle your own marital problems. You are very busy getting on with your own lives and it doesn't make much sense going to counselling sessions when you are feeling well and in control of your life.

In closing, we send you greetings for a Merry Christmas and wish you all the very best for a Happy New Xear.

Sincerely,

Peggy Simpson, RN, BN Lorraine M. Wright, RN, PhD Graduate Student Director, Family Nursing Unit Professor, Faculty of Nursing and other members of our clinical team.

During the final session we also explained that when couples take a new direction in life, they often encounter setbacks. Tom and Sandy were able to discuss contingency plans should this occur.

\section{ANALYSIS AND EVALUATION OF SYSTEMIC BELIET THERAPY}

In the letters, the seizures were externalized and a second on complementary description evolved. Distinctions were drawn forth in which Tom was dedicated to making the marriage work and Sandy was responsible, mature and in possession of a increased inner strength. The letters punctuated the power and control the couple had over the influence of the seizures. The purpose was to embed the distinctions that were more facilitative for the family system.

The letters were also designed to increase the impact of our therapeutic conversations by adding intensity through repetition, by continuing the dialogue, and by putting into written form selected interactions and interventions evolving in the session. Of course, the overall hope was that new facilitative beliefs about themselves, their marriage and the spells would emerge that would replace their previously held constraining beliefs. On receipt of the letters the family 
can also establish their own rituals and feedback loops that can enhance the treatment process beyond therapy (Wood \& Uhl, 1988).

The family's responses to new ideas and beliefs were evaluated by our clinical team at the beginning of each session. This was accomplished by asking each family member what "stood out for them" from the previous session. This gave us salient information about which opinions, comments, and/or beliefs that were offered perturbed the family system. Pamilies respond to those perturbations which fit for their particular structurally determined organization (Maturana \& Varela, 1987). Sandy and Tom were very explicit about what "stood out for them". They stated that the greatest impact on them was the positive reedback given to them as individuals and as a couple. The couple also vividly remembered the intrusive spell. Tom stated the spell was very rude the way it entered and tried to take over. The first letter had further dramatic perturbing effects. Sandy stated the information in the letter corresponded to how she was beginning to think about herself. Sandy commented that the information in the first letter had given her a new outlook and attitude about herself. "It made me look at my life and realize I do have accomplishments." Tom liked the positiveness and said he felt more relaxed and could speak his mind more freely. The couple stated that the letters remind them of what went on in the sessions. Sandy stated: "We are in our own home with our letter and we can communicate about some of our problems. We could face them ourselves and talk about them."

The letters were also useful in perturbing the couple's beliefs re. garding the infuence of the spells in diverting their attention from their marital concerns. Instead of remaining symmetrical over the spells, they became united against them which enabled them to gain confidence to tackle their marital problems. The couple realized they did have a great deal of control over the influence the seizures had in their family life.

\section{CONCLUSION}

Epilepsy and marital conflict is a daunting experience for any couple. This case study described the role and interaction of constraining beliefs surrounding epilepsy and marital conflict with a couple and the health care professionals. Profound changes occurred in the family belief system when the couple were offered alternate beliefs about the seizures, themselves and the health care system. 
Alternate beliefs were introduced in the form of interventive questions, externalization of the seizures and therapeutic letters. Externalizing the problem of epileptic seizures also assisted in uniting the couple in their struggle to gain an increased sense of control and automony in their lives. Systemic Belief Therapy focuses on identifying those beliefs which are constraining and providing alternate facilitative beliefs for families consideration. Systemic Belief Therapy appears promising in assisting families to cope more successfully with the challenges and intrusive interruptions of epileptic seizures and of other physical health problems.

\section{REFERENCES}

Adams, A., \& Victor, M. (1981), Principles of neurology. New York: McGraw Hill.

Boscolo, L., Cechin, G., Hofman, \& Penn, P. (1987). Milan systemic family therapy. Now York: Basic Books.

Dodrill, C., Beier, A., Kasparick, M., Tacke, I., Tacke, U., \& Siang-Yang Tan (1984). Psychosocial problems in adults with epilepsy: Comparison of findings from four countries, Epilepsia, 25(2), 168-175.

Epston, D. (1986). Writing your biography. Family Therapy Case Studies, 1(1), 13-18.

Harkaway, J., E., \& Madsen, W. C. (1989). A systemic approach to medical non-compliance: The case of chronic obesity. Family Systems Medicine, 7(1), 42-65.

Kerns, A., \& Curley, A. (1985). A biopsychosocial approach to illness and the family. In D. Turke \& A. Kermo (Eds.), Healh, illness and families (pp. 146-182). Toronto: John Wiley \& Sons.

Masland, A. L. (1985). Psychosocial aspects of epilepsy. In A. Porter and P. Marselli (Eds.), The epilepsies (pp. 356-377). Toronto: Butterworth \& Co.

Maturana, H. A., \& Varela, F.J. (1987). The tree of knowledge. Boston: New Science Library.

Mittan, A., Locke, G., \& Gatica, M. (1983). Epileptics' attitudes toward finding and maintaining employment. 15th Epilepsy International Symposium (Abstract, p. 20). Washington, DC: September 26030.

Needham, A. (1972). Beliefs, language and experience. Oxford: Blackwell.

Rolland, J. (1987). Family illness paradigms; Evaluation and significance. Family Systems Medicine, 5, 482-502.

Schoenberg, B. (1985). Epidemiology of epilepsy. In A. Porter \& P. Morselli (Eds.), The Epilepsies (pp. 94-105). Toronto: Butterworth \& Co.

Thompson, K. (1986). Beliefs and ideology. New York: Tavistock Publications.

Tomm, K. (1989). Externalizing the problem and internalizing personal agency. Journal of Strategic and Systemic Therapies, $1(1), 54-59$.

Tomm, K. (1988). Interventive interviewing. Part III. Intending to ask lineal, circular, strategic or reflexive questions? Family Process, $27,1-15$.

White, M. (1986), Negative explanation, restraint and double description: A template for family therapy. Family Process, 25, 169-184.

White, M. (1984). Pseudo-encopresis: From avalanche to victory, from vicious to virtuous circles. Family Systems Medicine, 2, 150-160.

White, M. (1988). The process of questioning: A therapy of literary merit. Dulwich Centre Newsletter, 8-14. 
White, M., E Eston, M. (1989). Literature means to therapewtc ends. Adelaide, South Australia: Dulwich Centre Publications.

Wood, C., Uhl, N. (1988). Post-session letters: Reverberations in the farnily treat ment process, Journal of Shategic and Systemic Therapies, $7(3), 25-72$.

Wright, L. M. (1990). When clients ask questions: Enriching the therapentic conversation. Family Therapy Netwarker, $15-16$.

Wright, L. M., 恳 Leahey, M. (1987), Fanulies and chronic ilness: Assumptions, assessment and intervention. In L. M. Wright \& M. Leahey (Wds), Families and chronic ilness (pp. 55-77). Springhouse, PA: Springhouse Book Carporation.

Wright, L. M., \& Leahey, M. (1984). Nurses and familes: A guide to fanily assessment and intervention. Philadelphia: F. A. Davis Co.

Wright, L. M., Watson, W. L. (1988). Systemic family therapy and family development. In C. Falicov (Ed.), Family transitions: Contulty and change over the life cycle (pp. 407-430). New York: Guilford.

Wright, L. M., Watson, W. L., \& Bell, J. M. (1990). The Fanily Nuring Unit: A unique integration of research, education and clinical practice. In $\mathrm{J} . \mathrm{M}$. Bell, W. L. Watson, and L. M. Wright (Eds.), The cutting edge of family nursing (pp. 95-112). Calgary, AB: Family Nursing Unit Publications.

Ziegler, A. (1982). Epilepsy: Individual ilness, human predicament. Family Relations, $31,485-444$ 